\title{
Immunodominant T-Cell Epitopes of Rubella Virus Structural Proteins Defined by Synthetic Peptides
}

\author{
MICHELINE MCCARTHY, ${ }^{1} \dagger$ AMY LOVETT,${ }^{1}$ RONALD H. KERMAN, ${ }^{2}$ \\ ANDRA OVERSTREET, ${ }^{1}$ AND JERRY S. WOLINSKY ${ }^{1 *}$ \\ Departments of Neurology ${ }^{1}$ and Surgery, ${ }^{2}$ The University of Texas Health \\ Science Center at Houston, P.O. Box 20708, Houston, Texas 77225
}

\begin{abstract}
Sets of overlapping synthetic peptides containing predicted T-cell epitope motifs were designed from the murine monoclonal antibody-defined map of linear B-cell epitope domains within each of the structural proteins of rubella virus (RV). The peptides represented well-defined subsequences of two capsid domains $\left(C_{1}\right.$ to $C_{29}$ and $C_{64}$ to $C_{97}$ ), of a domain of glycoprotein $E 1$ containing neutralizing determinants $\left(E 1_{202}\right.$ to $\left.E 1_{283}\right)$, and of a domain of glycoprotein $E 2\left(E 22_{31}\right.$ to $\left.E 2{ }_{105}\right)$. With the exception of peptides representing $C_{64}$ to $C_{97}$, each set of peptides stimulated varied but individually specific lymphoproliferative responses in peripheral blood mononuclear cells from 25 to $50 \%$ of a representatively large number of normal, $R V$-immune human donors with diverse human leukocyte antigen (HLA) backgrounds. Responses were mediated by CD4 ${ }^{+}$T cells in association with HLA class II antigens, though lymphoproliferative responses to a given peptide were usually not HLA-DR allele specific. Correlation analysis of responses to overlapping peptides suggests that there is an immunodominant T-proliferative epitope within $C_{14}$ to $C_{29}$ recognized by approximately $50 \%$ of the donor population. However, limiting-dilution analysis indicated much variability between individuals in lymphocyte recognition of this T-cell determinant, even within similar HLA-DR contexts. Thus, the fine specificity of relatively immunodominant T-cell epitopes may vary from individual to individual. Synthetic peptides with predicted T-cell motifs have proved to be useful probes of the molecular determinants of cellular immunity to $R V$ and should expand the rational basis for the design of synthetic RV vaccines.
\end{abstract}

Understanding the determinants of human immunity to rubella virus $(R V)$ is a necessary first step to effective prevention of an infection which may have catastrophic immunopathological consequences, including the congenital rubella syndrome, progressive rubella panencephalitis, diabetes mellitus, or arthritis $(51,52) . \mathrm{RV}$ is the sole member of the Rubivirus subgroup of the togaviruses. The virion contains three structural proteins: two glycoproteins designated E1 and E2, and a nonglycosylated, phosphorylated capsid (C) protein surrounding a message-sense RNA genome. The complete nucleic acid sequence and derived primary structure of the virus are known (11). Available structural and functional data suggest that $\mathrm{E} 1$ is the dominant surface molecule of the virus and the main target for the host's humoral immune response (reviewed in reference 52). Anti-E2 and anti-C immunoglobulin $G$ are also found in the majority of immune normal subjects (9) but in lower relative proportions (35). Linear domains containing B-cell epitopes have been defined for all of the RV structural proteins on the basis of murine monoclonal antibody (MAb) mapping under protein-denaturing conditions (53). These domains could be represented by synthetic peptides (SPs) of approximately 30 amino acids or less. Similar linear B-cell epitopes have been identified within SPs representing subsequences of measles virus glycoproteins (37) and respiratory syncytial virus proteins $(43,48,49)$, among others, and may have potential as immunogenic vaccines. SPs containing linear B-cell determinants within the $\mathrm{N}$-terminal region of the $R V$ capsid $\left(C_{1}\right.$ to $\mathrm{C}_{29}$ ) were immunogenic in $\mathrm{BALB} / \mathrm{c}$ mice and induced a vigorous humoral immune response cross-reactive with intact RV antigen (26). However, polyclonal antibody gener-

\footnotetext{
* Corresponding author.

$\dagger$ Present address: Department of Neurology, University of Miami School of Medicine, Miami, FL 33151.
}

ated by $\mathrm{RV}$-infected BALB/c mice reacted with intact RV antigen but not with capsid SPs of 21 or fewer residues (27). Slightly longer SPs within this region (31 residues) have been reported to bind mouse antisera to whole capsid protein or RV antigen (36).

$\mathrm{RV}$-specific cellular immune responses measured in vitro include lymphocyte proliferation, lymphocyte-mediated cytotoxicity, and lymphokine secretion $(5,16,46)$. These responses persist at low levels in immune individuals. While the lymphoproliferative response to $\mathrm{RV}$ antigen is restricted by major histocompatibility complex (MHC) class II antigens, little is known about the specific determinants of cellular immunity to the structural proteins of this virus. Using a nested set of overlapping SPs comprising the capsid protein, Ou et al. (36) identified one relatively immunodominant sequence within the RV capsid that was recognized by a small group of MHC-diverse, RV-immune human donors. This sequence, $C_{255}$ to $C_{280}$, included a four-amino-acid T-cell epitope motif predicted by an algorithm which recognizes T-cell epitopes within amphipathic $\alpha$ helices (41). Similar strategies using SPs with predicted motifs have identified $\mathrm{T}$-cell epitopes in human immunodeficiency virus glycoproteins $(3,4)$, varicella-zoster virus glycoproteins II and IV (14), measles virus fusion protein (38), and influenza virus hemagglutinin and matrix proteins (40).

In this study, sets of overlapping SPs containing predicted $\mathrm{T}$-cell epitope motifs were designed from the murine MAbdefined map of linear B-cell epitope domains within each of the RV structural proteins (53). The SPs were then used to probe the molecular determinants of the cellular immune response to $\mathrm{RV}$ in an MHC-diverse, normal adult human population. This work expands the definition of the pattern of dominant $\mathrm{T}$-cell epitopes active in normal human RV immunity and supports the rational basis for the design of synthetic RV vaccines. 


\section{MATERIALS AND METHODS}

SPs. The SPs initially were designed as short sequences (20 to 35 amino acids) within linear B-cell epitope-containing domains of $E 1, E 2$, or $C$ as defined by MAb studies (53). The sequences for the SPs were further selected for the occurrence of predicted T-cell epitope motifs by the algorithm of Rothbard and Taylor (41). On the basis of these analyses, sets of overlapping SPs containing putative T-and/or B-cell epitopes were fabricated. As previously reported in detail (53), peptides were synthesized in milligram quantities in C-terminal-to-N-terminal direction by Merrifield solid-phase methodology based on standard tert-butyloxycarbonyl (tBOC) amino acid protocols, using an automated peptide synthesizer. Analytical quantities of peptides were generated from $10-\mathrm{mg}$ peptide-resin aliquots removed after every coupling step. For release and deblocking of peptide, a micro-trifluoromethanesulfonic acid (TFMSA) cleavage method was used to generate a set of nested SPs at progressive stages of synthesis at the $\mathrm{N}$-terminal end (33). This strategy provides a means to "walk down" the N-terminal primary sequence and identify critical residues for T-cell function in a small number of donors. However, the yield of peptide from such stepwise synthesis was insufficient to screen the entire immune donor population. To account for the effects of amino acid substitutions on overall peptide conformation, molecular dynamics using the CHARMM program was applied as a searching algorithm for conformational exploration and comparison of peptides (39).

Normal donors. Heparinized blood samples were obtained from members of a panel of individuals who regularly donate blood on a rotating basis to provide normative data on histocompatibility type matching for the Histocompatibility and Immune Evaluation Laboratory of The University of Texas Health Science Center at Houston. All donors were in good health, without any remarkable medical history or chronic illness. The panel of normal adult donors assayed included 58 females and 47 males of diverse ethnic backgrounds and MHC types. MHC class I and DR (MHC class II) types were determined by microcytotoxicity (21). Ninetyeight percent (103 of 105) of these individuals have immunoglobulin $G$ antibody to RV, as measured by enzyme-linked immunosorbent assay (ELISA) using previously detailed methods (34), and $90 \%$ show in vitro lymphoproliferation to intact RV antigen with a stimulation index (SI) of $\geq 2$ (see below). By history, immunity was acquired through natural infection in childhood and/or vaccination. Two individuals lacked both humoral and cellular markers for RV immunity, as measured by the ELISA and in vitro lymphoproliferation assays.

Preparation of PBMCs and lymphoproliferative assay. Fresh peripheral blood mononuclear cells (PBMCs) were isolated on one-step Ficoll-sodium metrizoate (Lymphoprep; Nycomed AS, Oslo, Norway) gradients. Washed cells were resuspended in RPMI 1640 medium with $10 \%$ pooled, heat-inactivated human AB serum (RPMI-AB) and plated at $10^{5}$ cells in $0.2 \mathrm{ml}$ per well in 96-well round-bottom tissue culture plates (Corning Glass Works, Corning, N.Y.). The presence of low amounts of anti-RV antibody in the human $\mathrm{AB}$ serum did not affect the lymphoproliferative responses to either RV or the SPs (data not shown). SP (20 $\mu \mathrm{g} / \mathrm{ml}$ ), or UV-irradiated RV (25) hemagglutinating units per $\mathrm{ml}$ ) grown in Vero cells and purified on discontinuous sucrose gradients (50), was added to quadruplicate PBMC cultures; controls consisted of cultures without added antigen. Cultures were incubated for 5 days at $37^{\circ} \mathrm{C}$ in a humidified $10 \% \mathrm{CO}_{2}$ atmosphere, and cell proliferation was then assayed by $\left[{ }^{3} \mathrm{H}\right]$ thymidine $(4 \mu \mathrm{Ci} / \mathrm{ml})$ uptake over $18 \mathrm{~h}$. Cultures were harvested onto glass fiber filter disks in a semiautomated multiwell harvester (Cambridge Technology, Watertown, Mass.). Dried filter disks were counted in Universol (ICN Biochemicals, Irvine, Calif.) scintillation cocktail in a Beckman LS 1800 scintillation counter. The average counts per minute (cpm) of quadruplicate samples was calculated for each culture condition. Data were recorded as change in uptake (cpm [antigen-stimulated] - cpm [control]) or SI (cpm [antigen-stimulated]/cpm [control]). To determine a baseline for nonspecific proliferation, the mean counts per minute plus 2 standard deviations was calculated from quadruplicate samples of control cultures. We found this number to be consistently less than an SI of 2 , thus setting our lower limit for designating a positive lymphoproliferative response to an SP as an SI of $\geq 2$. For data review and statistical analysis, computer-based data files were maintained with Complete Statistical Systems software (Statsoft, Tulsa, Okla.).

Limiting dilution analysis. Limiting dilution cultures were prepared in 96-well round-bottom tissue culture plates. PBMCs were seeded at $1 \times 10^{5}, 5 \times 10^{4}, 2 \times 10^{4}, 1 \times 10^{4}$, or $1 \times 10^{3}$ viable cells per well in replicates of 12 wells. Irradiated (3,000 rads) autologous PBMCs were mixed with viable cells to maintain a constant total cell number of $10^{5}$ cells per well. Parallel cultures were then incubated with SP at $20 \mu \mathrm{g} / \mathrm{ml}$ or without added antigen for 7 days at $37^{\circ} \mathrm{C}$ in a humidified $10 \% \mathrm{CO}_{2}$ atmosphere prior to assay of cell proliferation by $\left[{ }^{3} \mathrm{H}\right]$ thymidine uptake as described above. The SP-containing responder wells were those with total $\left[{ }^{3} \mathrm{H}\right]$ thymidine counts per minute greater than the mean counts per minute plus 2 standard deviations in parallel antigen-free control wells containing the same number of viable cells. Data were plotted as percent nonresponder wells versus the number of viable cells per well. Precursor cell frequency was calculated from the $x$ intercept at $37 \%$ nonresponder wells (23).

Isolation of $\mathbf{T}$ cells. T-cell-enriched lymphocyte suspensions were obtained by nylon wool fiber (Polysciences, Inc., Warrington, Pa.) column filtration of PBMCs (18). To isolate lymphoblasts after antigen-specific activation, PBMCs were centrifuged through five-step discontinuous Percoll density gradients (90/60/50/40/30\%; density range, 1.035 to 1.103 $\mathrm{g} / \mathrm{ml}$ ). Lymphoblasts were recovered from the $30 / 40 \%$ and 40/50\% interfaces, pooled, washed in Hanks' basic salts solution, and resuspended in RPMI-AB. Cell phenotype analysis was performed by immunofluorescent labeling of cell surface antigen markers with specific fluorescent MAbs (Becton Dickinson, Mountain View, Calif.) and by flow cytometry (FACScan flow cytometer; Becton Dickinson).

MAb blocking studies. Hybridoma cell culture supernatant fluid containing MAbs to monomorphic determinants of the HLA class II protein (L243), to human CD4 antigen (OKT4), or to human CD8 antigen (OKT8) were added at $37 \%$ (vol/vol) to antigen-stimulated PBMC cultures or their controls at the time of initiation of the culture. Hybridoma cell lines (ATCC HB55 for L243, ATCC CRL8002 for OKT4, and ATCC CRL8014 for OKT8) were obtained from the American Type Culture Collection. Inhibition of antigenstimulated proliferation by MAbs was calculated as \% inhibition $=\{1-[(\mathrm{cpm}$ with peptide plus $\mathrm{MAb})-(\mathrm{cpm}$ with $\mathrm{MAb})] /[(\mathrm{cpm}$ with peptide $)-(\mathrm{cpm}$ with medium $)]\} \times 100$ (24). 
CAPSID aa 1-29

\begin{tabular}{lcc}
\hline Peptide & Capsid & Sequence \\
\hline SP1 & $1-18$ & MASTIPITMEDLQKALEA \\
SP2 & $14-29$ & KALEAQSRALRAELAA \\
SP8 & $9-29$ & MEDLQKALEAQSRALRAELAA \\
SP14 & $9-22$ & MEDLQKALEAQSRA \\
SP16 & $11-29$ & DLQKALEAQSRALRAELAA \\
SP19 & $11-29 *$ & DLQKSLEAQS RALRAELAA
\end{tabular}

CAPSID aa 64-97

\begin{tabular}{lrr}
\hline Peptide & Capsid & Sequence \\
\hline SP9 & $78-97$ & PPPPEERQETRSQTPAPKPS \\
SP10 & $64-97$ & GNRGRGQRRDWSRAPPPPEERQETRSQTPAPKPS
\end{tabular}

E1 aa 202-283

\begin{tabular}{lcc}
\hline Peptide & E1 & Sequence \\
\hline SP11 & $202-225$ & DLVEYIMNYTGNQQSRWGLGSPNC \\
SP15 & $208-239$ & MNYTGNQQSRWGLGSPNCHGPDWASPVCQRHS \\
SP12 & $226-247$ & HGPDWASPVCQRHSPDCSBLVG \\
SP7 & $243-266$ & SBLVGATPERPRLBLVDADDPLLR \\
SP13 & $262-283$ & DPLLRTAPGPGEVWVIPVIGSQ
\end{tabular}

E2 aa 31-105

\begin{tabular}{llcl}
\hline Peptide & E2 & \multicolumn{3}{c}{ Sequence } \\
\hline SP21 & $31-55$ & QLPFLGHDGHHGGTLRVGQHYRNAS & \\
SP22 & $51-75$ & YRNASDVLPGHWLQGGWGCYNLSDW & \\
SP23 & $81-105$ & VCHTKHMDFWCVEHDRPPPATPTPL
\end{tabular}
(41).

FIG. 1. SPs representing overlapping subsequences of RV structural protein domains. Underlined sequences are predicted T-cell motifs

\section{RESULTS}

SP design. The initial set of peptides (Fig. 1) included SP1, SP2, and SP8 within $\mathrm{C}_{1}$ to $\mathrm{C}_{29}$ plus SP9 and SP10 within $\mathrm{C}_{64}$ to $\mathrm{C}_{97}$. The SP8 $\left(\mathrm{C}_{9}\right.$ to $\left.\mathrm{C}_{29}\right)$ peptide had previously been shown to bind MAbs (C-1, C-2, and C-8) specific for the $\mathrm{N}$-terminal capsid region, while SP10 binds MAb C-9 (53). Next, SP16 $\left(\mathrm{C}_{11}\right.$ to $\left.\mathrm{C}_{29}\right)$ was designed from MAb-binding studies of micro-TFMSA cleavage peptides that further defined the $\mathrm{N}$-terminal ends of the linear $\mathrm{B}$-cell epitopes within $C_{1}$ to $C_{29}$ at $C_{13}$ and $C_{12}$ (55). Two additional peptides were designed on the basis of $\mathrm{T}$-cell motif predictions. One, SP14 $\left(C_{9}\right.$ to $\left.C_{22}\right)$, was designed to truncate a predicted T-cell motif within $\mathrm{C}_{21}$ to $\mathrm{C}_{24}$ (RALR) at its C-terminal end. The other, SP19 $\left(C_{11}\right.$ to $\left.C_{29}\right)$, was designed with an Ala $\rightarrow$ Ser substitution at $\mathrm{C}_{15}$ which disrupts a predicted $\mathrm{T}$-cell motif within $C_{14}$ to $C_{17}$. The predicted helical conformation of sequence $C_{11}$ to $C_{29}$ was analyzed by computer-based algorithms and was not altered by the Ala $\rightarrow$ Ser substitution at $\mathrm{C}_{15}$ (data not shown). The E1 peptides, SP7, SP11, SP12, SP13, and SP15, represent overlapping sequences within $\mathrm{E}_{202}$ to $\mathrm{El}_{283}$, a linear B-epitope domain that binds neutralizing MAbs E1-18 and E1-20 (53). Of note, SP15 is a peptide that contains domains for binding both murine and human neutralizing antibody $(32,56)$. A later additional set of peptides was developed from sequences within a 116-residue domain at the amino terminus of E2: SP21 (E2 $2_{31}$ to $\left.E 2_{55}\right)$, SP22 (E2 51 to E2 $2_{75}$ ), and SP23 (E2 $2_{81}$ to $\left.E 2_{105}\right)$. This domain contains linear B-cell determinants recognized by six MAbs designated E2-1 through E2-1 through E2-6 (53). Peptides SP21 and SP22 each contain predicted T-cell motifs, while SP23 contains an antibody-combining site (E2 $2_{93}$ to E2 ${ }_{98}$ ) predicted by hydrophilicity index (17).

T-cell proliferative responses to peptides. Peptide-specific lymphoproliferation was initially assayed at peptide concen- trations of $10,20,50,75$, and $100 \mu \mathrm{g} / \mathrm{ml}$. Lymphoproliferative responses increased with peptide concentration to a maximum at $20 \mu \mathrm{g}$ of peptide per ml (data not shown). The magnitude of proliferative responses to peptides or RV antigen, as measured by SI values, varied among donors. However, the SI values obtained for peptide-stimulated or $\mathrm{RV}$-stimulated responses from an individual donor were similar, and donor specific response patterns were reproducible over time. Individuals who had positive lymphoproliferative responses to specific peptides were identified after multiple trials (Tables 1 to 3 ). There were no significant peptide-specific lymphoproliferative responses from either of the two donors who lacked both humoral and cellular immune markers to RV (data not shown). There were some individuals who consistently had lymphoproliferative responses with an SI of $\geq 4$ to certain peptides. These individuals were arbitrarily designated high responders. Data from high responders to several of the E1 SPs are illustrated in Fig. 2.

Several individuals showed lymphoproliferative responses to one or more of the E1 peptides SP7, SP11, SP12, and/or

TABLE 1. Proportions of RV-immune individuals with positive lymphoproliferative responses to capsid SPs

\begin{tabular}{lrrrrrrr}
\hline & \multicolumn{7}{c}{ No. responding/no. assayed } \\
\cline { 2 - 7 } SI $^{a}$ & SP1 & SP2 & SP8 & SP14 & SP16 & SP19 & $\begin{array}{c}\text { Any } C_{1}-C_{29} \\
\text { SP }(\%)\end{array}$ \\
\hline$\geq 2$ & $16 / 73$ & $20 / 72$ & $20 / 61$ & $2 / 49$ & $9 / 23$ & $6 / 12$ & $37 / 73(50)$ \\
$\geq 4$ & $4 / 73$ & $6 / 72$ & $8 / 61$ & $1 / 49$ & $4 / 23$ & $2 / 12$ & $14 / 73(19)$ \\
\hline \multicolumn{7}{c}{ Assignment is based on the median SI of three or more trials or the } \\
average of two trials for all individuals. For a given peptide, those individuals \\
with an SI of $\geq 4$ constitute a subset of those with an SI of $\geq 2$.
\end{tabular}


TABLE 2. Proportions of RV-immune individuals with positive lymphoproliferative responses to E1 SPs

\begin{tabular}{lrrrcrr}
\hline & \multicolumn{5}{c}{ No. responding/no. assayed } \\
\cline { 2 - 7 } SI $^{a}$ & \multicolumn{1}{c}{ SP7 } & SP11 & SP12 & SP13 & SP15 & $\begin{array}{c}\text { Any E1 SP } \\
(\%)\end{array}$ \\
\hline$\geq 2$ & $15 / 72$ & $14 / 45$ & $7 / 44$ & $7 / 46$ & $1 / 35$ & $27 / 72(38)$ \\
$\geq 4$ & $5 / 72$ & $3 / 45$ & $1 / 44$ & $0 / 46$ & $0 / 35$ & $7 / 72(10)$ \\
\hline
\end{tabular}

${ }^{a}$ See Table 1, footnote $a$.

SP13, but only one individual showed a positive but low response to SP15 (Table 1). All five high responders to SP7 had HLA DR3 or its associated allele DRw17. Among all responders to SP7, the frequency of DR3 was 0.75 . This is a statistically significant increase in the frequency of the DR3 type, which in the entire donor population had a frequency of 0.23 (high responders, $\chi^{2}=12.55, P \leq 0.005$; among all responders, $\left.\chi^{2}=8.36, P \leq 0.04\right)$. There were also multiple responders to the set of overlapping peptides within $C_{1}$ to $\mathrm{C}_{29}$ with the exception of SP14, the capsid peptide truncated within a predicted T-cell motif. Only 2 individuals among 47 tested had a consistent lymphoproliferative response to SP10 $\left(\mathrm{C}_{64}\right.$ to $\left.\mathrm{C}_{97}\right)$, a sequence which lacks any predicted $\mathrm{T}$-cell motif. Neither of these individuals showed lymphoproliferative responses to SP9, which contains the C-terminal half of SP10 $\left(C_{78}\right.$ to $\left.C_{97}\right)$. Multiple responders to E2 peptides SP21, SP22, and SP23 were identified. The frequency of high responders to the E2 domain represented by these SPs (12\%) was lower than the frequency of high responders to the capsid (19\%) and approximately the same as to the E1 $(10 \%)$ domains (Table 2). No statistically verifiable MHC restriction of in vitro lymphoproliferative responses to capsid or E2 SPs emerged.

To determine the relative importance of $T$ and $B$ cells to the proliferative response observed, peptide-stimulated proliferation was reassayed with $\mathrm{T}$-cell-enriched and B-cellenriched lymphocyte samples. Cells used in these assays were prepared by nylon wool filtration of PBMCs from donors 3, 109, and 38. By flow cytometry, the T-cellenriched fraction contained 96 to $99 \%$ CD2 ${ }^{+} \mathrm{T}$ cells, while the B-cell-enriched fraction contained 50 to $70 \%$ Leu $12^{+} \mathrm{B}$ cells and 30 to $40 \%$ T cells. Autologous irradiated PBMCs were added back to the assay cultures as antigen-presenting cells. These assays confirmed that specific proliferation observed with PBMCs derived principally from the T-cell population. All peptide-stimulated B-cell-enriched cultures showed an SI of $<2$, while the pattern of peptide-specific proliferation in $\mathrm{T}$-cell-enriched cultures paralleled that of the unseparated PBMC cultures (data not shown).

Phenotype and MHC restriction of $T$ cells responding to peptides. To assess the importance of $\mathrm{T}$-cell surface antigens in mediating peptide-specific lymphoproliferation, lymphocytes from high responders were incubated with peptides in the presence of MAb to CD4, to CD8, or to monomorphic determinants of HLA-DR (Fig. 3). When CD4 determinants were blocked by MAb OKT4, peptide-specific proliferation was inhibited by $\approx 80 \%$. Blockade of CD8 determinants by MAb OKT8 did not significantly inhibit $(\approx 2$ to $15 \%)$ capsid peptide-specific proliferation. OKT8 inhibited SP7-specific proliferation by $40 \%$ in one of two high responders tested but stimulated such proliferation by a moderate amount $(\approx 70 \%)$ in the second high responder (data not shown). This effect may have been due to blocking of SP7-primed suppressor or cytotoxic activity seen with lymphocytes from some high SP7 responders (29). Blockade of HLA-DR with MAb L243 inhibited peptide-specific proliferation by $\approx 80$ to $90 \%$.

Phenotype analysis of $\left[{ }^{3} \mathrm{H}\right]$ thymidine-labeled lymphocytes was performed to determine which cells proliferated in cultures stimulated by SPs. Peptide-stimulated and control cultures were labeled on day 5 with $\left[{ }^{3} \mathrm{H}\right]$ thymidine for $16 \mathrm{~h}$. Cells were then centrifuged through Percoll density gradients to separate the dividing cells that were differentially labeled with thymidine. Peptide-stimulated cultures yielded a distinct broad peak of $\left[{ }^{3} \mathrm{H}\right]$ thymidine label with a mean density of $\approx 1.06 \mathrm{~g} / \mathrm{ml}$ (data not shown). No such radiolabeled peak was present in gradients prepared from $\left[{ }^{3} \mathrm{H}\right]$ thymidine-labeled control cultures. Cell phenotype analysis of

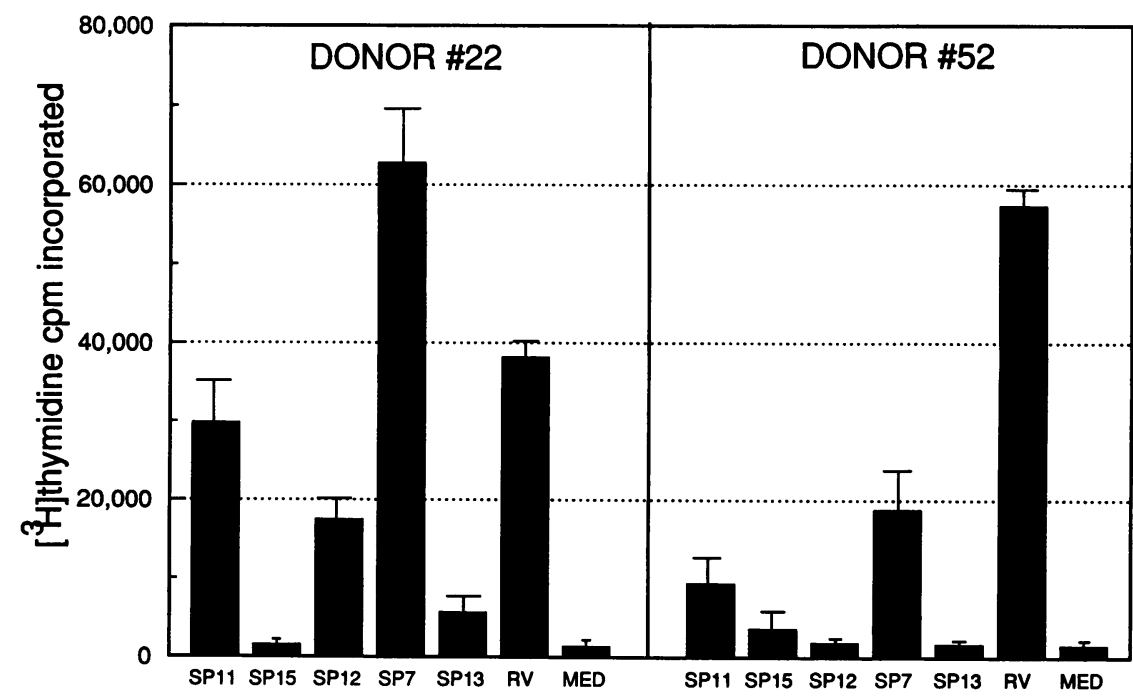

FIG. 2. Lymphoproliferative responses of two high responders to overlapping $S P s$ within $E 1_{202}$ to $E 1_{283}$ or to intact $\mathrm{RV}$ antigen (RV). MED, spontaneous proliferation in cultures incubated with medium only. The data shown represent the mean \pm standard deviation of quadruplicate samples from a single experiment. The patterns of proliferation in this peptide panel are representative of several independent experiments with cells from these donors obtained several months apart. 
TABLE 3. Proportions of RV-immune individuals with positive lymphoproliferative responses to E2 SPs

\begin{tabular}{llllc}
\hline & \multicolumn{4}{c}{ No. responding/no. assayed } \\
\cline { 2 - 5 } SI $^{a}$ & SP21 & SP22 & SP23 & $\begin{array}{c}\text { Any E2 SP } \\
(\%)\end{array}$ \\
\hline$\geq 2$ & $2 / 17$ & $1 / 17$ & $4 / 17$ & $6 / 17(35)$ \\
$\geq 4$ & $1 / 17$ & $0 / 17$ & $1 / 17$ & $2 / 17(12)$ \\
\hline
\end{tabular}

${ }^{a}$ See Table 1 , footnote $a$.

gradient peaks from four peptide-stimulated high-responder cultures indicated that the predominant cell type in the gradient peak was the $\mathrm{CD}^{+} \mathrm{T}$ lymphocyte $(\approx 65$ to $75 \%)$, with lesser proportions of $\mathrm{CD}^{+} 6^{+}$natural killer cells $(\approx 1 \%)$ and $\mathrm{CD} 19^{+}$B-cells $(\approx 10 \%)$. Gradient peaks contained variable proportions of $\mathrm{T}$ lymphocytes expressing the CD4 marker (15 to $50 \%$ ) or the CD8 marker (3 to $40 \%$ ). However, more than $80 \%$ of $\mathrm{CD}^{+}$lymphocytes from the gradient peak also expressed the activation marker HLA-DR (Ia). Approximately half of these $\mathrm{CD}^{+} \mathrm{Ia}^{+}$lymphocytes expressed CDw29 (4B4), a marker for memory T cells that have been activated by prior exposure to antigen $(6,7)$. The predominant phenotype in parallel fractions from the control culture's gradient was the $\mathrm{CD}^{+} \mathrm{T}$ lymphocyte $(\approx 70$ to $90 \%)$, with lesser proportions of $\mathrm{CD}^{+} 6^{+}$natural killer cells $(\approx 3 \%)$ and $\mathrm{CD} 19^{+} \mathrm{B}$ cells $(\approx 14$ to $30 \%)$. Approximately $35 \%$ or less of $\mathrm{CD}^{+}$lymphocytes from the control gradient fractions also expressed the Ia activation marker.

Frequency of $\mathbf{T}$ cells responding to peptides. Limitingdilution analyses of lymphoproliferation were performed to determine whether peptide-specific T-cell proliferation followed single-hit kinetics that suggest the expansion of a single $\mathrm{T}$-cell clone presumed specific for a single T-determinant sequence in the peptide $(22,23)$. Limiting-dilution analyses were not uniform among the 10 high responders tested. In some cases, data fit a simple linear regression analysis (Fig. 4), with near overlap of data from limitingdilution cultures stimulated by SP2, SP8, and/or SP16 (Fig. 4 , donor 29). In other cases, data did not fit a linear analysis (data not shown).

In those cases in which limiting-dilution analysis followed

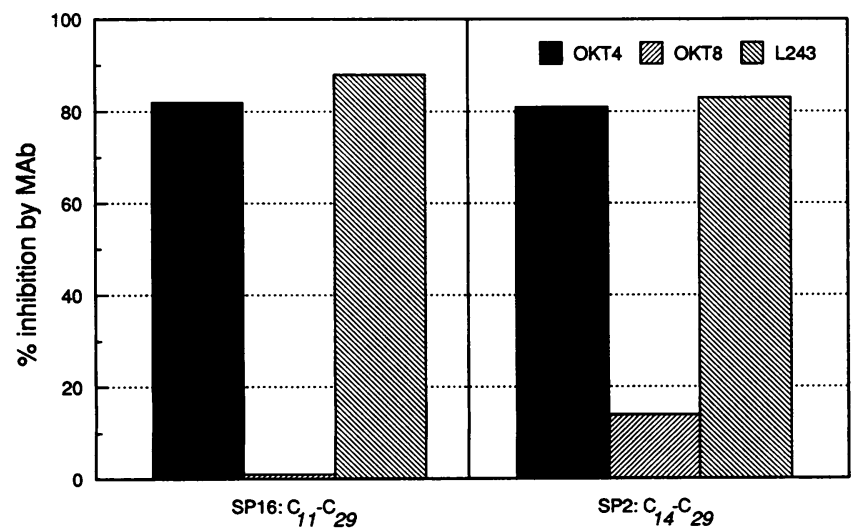

FIG. 3. MAbs to CD4 (OKT4) and to class II MHC (L243) block lymphoproliferative responses of high-responder donor 59 to overlapping peptides SP16 and SP2 within $\mathrm{C}_{11}$ to $\mathrm{C}_{29}$. MAb to CD8 (OKT8) did not significantly block the peptide-stimulated response. Proliferation and inhibition of proliferation were calculated as described in Materials and Methods.
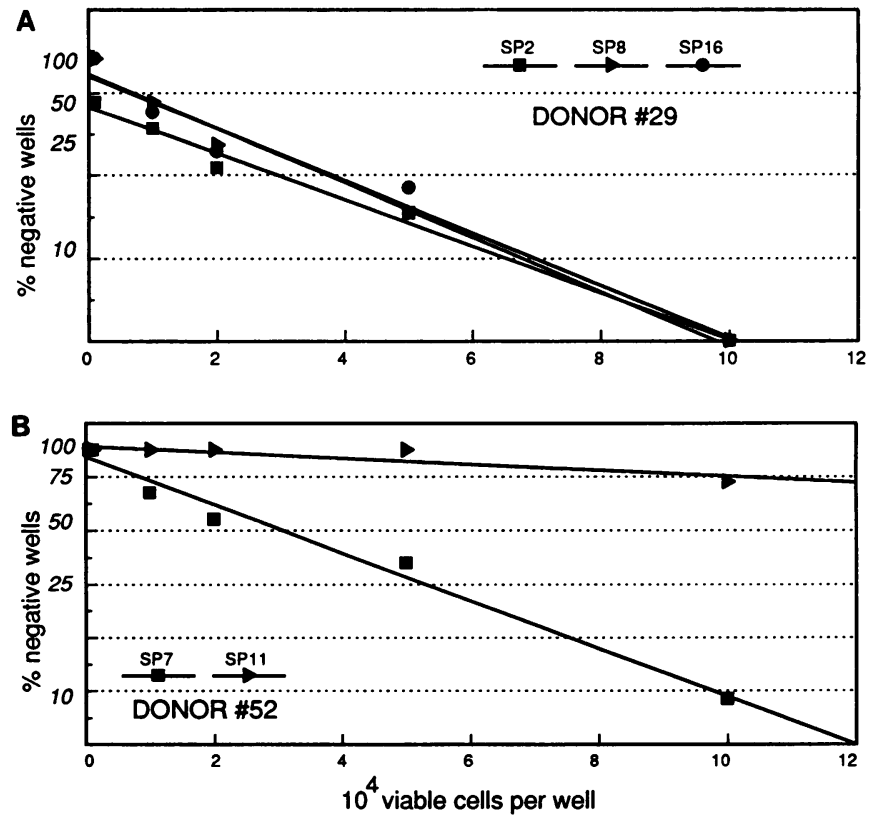

FIG. 4. Limiting-dilution analyses of lymphoproliferative responses of donor 29 to overlapping SPs within $C_{9}$ to $C_{29}(A)$ and of donor 52 to nonoverlapping SPs within $\mathrm{E}_{202}$ to $\mathrm{E}_{266}$ (B). Both donors are high responders to their respective set of peptides. Regression lines were calculated by the method of least squares.

linear or single-hit kinetics, peptide-specific T-cell precursor frequency was approximated from the linear regression data. Precursor values ranged from $1: 10,000$ to $1: 80,000$. For example, the precursor frequency of $\mathrm{T}$ cells specific for $\mathrm{C}_{14}$ to $\mathrm{C}_{29}$ (SP8) in donor 29 was estimated at 1:20,000 after correcting for background (23). In donor 52, the precursor frequency of $\mathrm{T}$-cells specific for $\mathrm{E} 1_{243}$ to $\mathrm{E}_{266}$ (SP7) was estimated at $1: 36,000$. The limiting-dilution analyses showed much variability between individuals in lymphocyte recognition of T-cell determinants present in SPs, even within similar HLA-DR contexts. Donors 38 and 52 both express HLA-DR3 alleles, but limiting-dilution analysis suggests, at least to a first approximation, that only $\mathrm{T}$ cells from donor 52 recognize an epitope in SP7 in a clonal fashion. However, the similarity of limiting-dilution analyses for SP2, SP8, and SP16 in a given donor among multiple trials suggests that whatever the $\mathrm{T}$-cell response to this region, single hit or multitarget (23), there is a T-cell determinant in common among these overlapping SPs.

Deducing minimum T-determinant sequences on SPs. Having established that SPs stimulate $\mathrm{T}$-cell activation and proliferation of lymphocytes from RV-immune normal human donors, we attempted to deduce the minimum amino acids delimiting the T-cell epitopes on these peptides. Since the peptides are overlapping, one would expect that comparison of lymphoproliferative responses to similar peptides would help delineate the amino acids necessary to drive the response. We used correlation analysis (8) to compare and correlate responses to overlapping or contiguous peptides within the capsid and $\mathrm{E} 1$ peptide responder populations (Tables 4 and 5). The comparatively small number of E2 peptide responders (six) and low number of trials performed precluded our obtaining statistically significant correlations for E2 SP responses.

Response correlations among capsid peptides fell into two 
TABLE 4. Correlations among lymphoproliferative responses to capsid SPs by Spearman's rank correlation coefficient

\begin{tabular}{llllllr}
\hline \multirow{2}{*}{ Peptide } & \multicolumn{7}{c}{ Correlation with $^{a}$ : } \\
\cline { 2 - 7 } & \multicolumn{1}{c}{ SP1 } & \multicolumn{1}{c}{ SP2 } & \multicolumn{1}{c}{ SP8 } & \multicolumn{1}{c}{ SP14 } & \multicolumn{1}{c}{ SP16 } & SP19 \\
\hline SP1 & 1.0 & 0.202 & 0.185 & $\mathbf{0 . 5 4 8}$ & -0.119 & -0.161 \\
SP2 & 0.202 & 1.0 & $\mathbf{0 . 7 0 9}$ & 0.090 & $\mathbf{0 . 5 9 5}$ & 0.469 \\
SP8 & 0.185 & $\mathbf{0 . 7 0 9}$ & 1.0 & 0.190 & $\mathbf{0 . 5 7 1}$ & $\mathbf{0 . 5 3 4}$ \\
SP14 & $\mathbf{0 . 5 4 8}$ & 0.090 & 0.190 & 1.0 & 0.021 & -0.011 \\
SP16 & -0.119 & $\mathbf{0 . 5 9 5}$ & $\mathbf{0 . 5 7 1}$ & 0.021 & 1.0 & $\mathbf{0 . 7 4 1}$ \\
SP19 & -0.161 & $\mathbf{0 . 4 6 9}$ & $\mathbf{0 . 5 3 4}$ & -0.011 & $\mathbf{0 . 7 4 1}$ & 1.0 \\
\hline
\end{tabular}

${ }^{a}$ An $r$ value of $>0.5$ indicates significant rank correlation at $0.1 \%(P \leq$ 0.001 ) for all peptides except SP19, for which there were fewer trials. For SP19, an $r$ value of $>0.5$ corresponds to significant correlation at $1 \%(P<$ $0.01)$. Data in boldface type indicate $r>0.5$.

groups: SP2, SP8, SP16, and SP19 in one group, and SP1 and SP14 in the second group. Highest correlations $(r>0.7)$ were between SP2 and SP8 and between SP16 and SP19. Among E1 SPs, the response to SP7 did not correlate with that to the other E1 SPs, despite overlap with SP12 on the $\mathrm{N}$-terminal end of SP7 and with SP13 on the C-terminal end of SP7. By contrast, responses to SP11, SP12, and SP13 showed pairwise correlation, despite lack of overlap among these peptides. The correlation analyses suggest that responders recognized a T-cell determinant common to SP2 $\left(C_{14}\right.$ to $\left.C_{29}\right)$, SP8 $\left(C_{9}\right.$ to $\left.C_{29}\right)$, and SP16 $\left(C_{11}\right.$ to $\left.C_{29}\right)$ but not present in SP14 $\left(C_{9}\right.$ to $\left.C_{22}\right)$. The $\mathrm{Ser} \rightarrow$ Ala substitution at $\mathrm{C}_{15}$ in SP19 does not affect lymphoproliferative responses in most responders. Thus, at least the $\mathrm{C}$-terminal end of the minimum $\mathrm{T}$-cell determinant must be within $\mathrm{C}_{23}$ to $\mathrm{C}_{29}$, and the $\mathrm{N}$-terminal end of the determinant must be within $\mathrm{C}_{14}$ to $\mathrm{C}_{29}$. Correlation analyses suggest that a second group of responders recognized a $T$-cell determinant common to SP1 $\left(\mathrm{C}_{1}\right.$ to $\left.\mathrm{C}_{18}\right)$ and SP14 $\left(\mathrm{C}_{9}\right.$ to $\left.\mathrm{C}_{22}\right)$, thus locating the minimum T-cell determinant within $\mathrm{C}_{9}$ to $\mathrm{C}_{18}$.

Within the E1 SPs, the correlation analyses are complex, perhaps in part because of detectable HLA-DR restriction of some responses. The lack of positive correlation between responses to SP15 and SP11 or SP12 is interesting in light of the extensive overlap among these peptides. There was only one significant responder to SP15 in our HLA-diverse, RV-immune population, although a predicted T-cell motif exists within the region of overlap between SP15 and SP12 $\left(E 1_{226}\right.$ to $\left.E 1_{239}\right)$. Several responders to SP11 or SP12 were identified. The SP12 responders may have recognized determinants $C$ terminal to the region of overlap with SP15, i.e., within $E 1_{240}$ to $E 1_{247}$. Similarly, SP11 responders may have recognized determinants $\mathrm{N}$ terminal to the region of overlap with SP15, i.e., within $E 1_{202}$ to $E 1_{207}$. Given the lack of response correlations with other E1 peptides, SP7 respond-

TABLE 5. Correlations among lymphoproliferative responses to E1 SPs by Spearman's rank correlation coefficient

\begin{tabular}{lcllll}
\hline \multirow{2}{*}{ Peptide } & \multicolumn{5}{c}{ Correlation with ${ }^{a}$ : } \\
\cline { 2 - 6 } & \multicolumn{1}{c}{ SP7 } & \multicolumn{1}{c}{ SP11 } & \multicolumn{1}{c}{ SP12 } & \multicolumn{1}{c}{ SP13 } & SP15 \\
\hline SP7 & 1.0 & 0.017 & 0.008 & -0.059 & 0.118 \\
SP11 & 0.017 & 1.0 & $\mathbf{0 . 5 3 4}$ & $\mathbf{0 . 5 0 1}$ & 0.098 \\
SP12 & 0.008 & $\mathbf{0 . 5 3 4}$ & 1.0 & $\mathbf{0 . 6 2 0}$ & 0.218 \\
SP13 & -0.059 & $\mathbf{0 . 5 0 1}$ & $\mathbf{0 . 6 2 0}$ & 1.0 & 0.193 \\
SP15 & 0.118 & $\mathbf{0 . 0 9 8}$ & 0.218 & 0.193 & 1.0 \\
\hline
\end{tabular}

${ }^{a}$ See Table 4, footnote $a$.
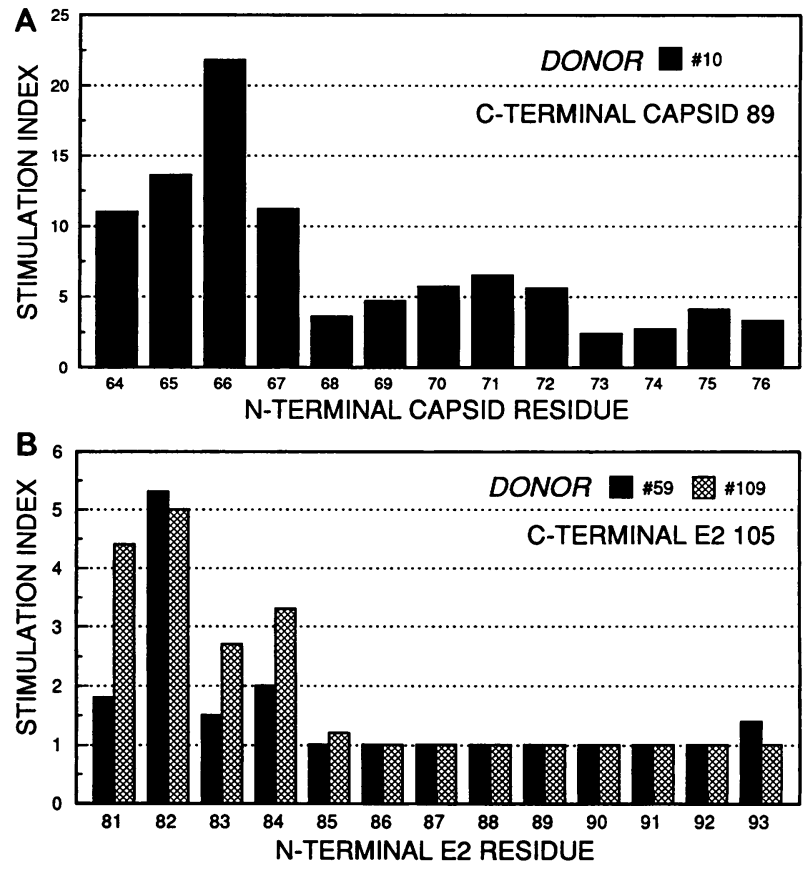

FIG. 5. Lymphoproliferative responses of PBMCs to nested SPs obtained by micro-TFMSA cleavage. (A) Cells from donor 10, a high responder to SP10 $\left(\mathrm{C}_{64}\right.$ to $\left.\mathrm{C}_{97}\right)$, were incubated with peptides encompassing $\mathrm{C}_{64}$ to $\mathrm{C}_{89}$ and having common C-terminal residue $\mathrm{C}_{89}$ while differing sequentially in $\mathrm{N}$-terminal capsid residue as indicated. (B) Cells from donors 59 and 109, two high responders to SP23 (E2 $2_{81}$ to $\left.E 2_{105}\right)$, were incubated with peptides encompassing $\mathrm{E} 2_{81}$ to $\mathrm{E} 2_{105}$ and having common C-terminal residue $\mathrm{E} 2_{105}$ while differing sequentially in $\mathrm{N}$-terminal $\mathrm{E} 2$ residue as indicated. $\mathrm{Re}-$ sponses measured as SI were calculated from $\left[{ }^{3} \mathrm{H}\right]$ thymidine uptake as described in Materials and Methods.

ers may have recognized T-cell determinants within $\mathrm{E} 1_{248}$ to $E 1_{261}$, a sequence unique to SP7. This sequence contains two predicted $\mathrm{T}$-epitope motifs.

In the capsid region $\mathrm{C}_{64}$ to $\mathrm{C}_{97}$ represented by peptides SP9 $\left(C_{78}\right.$ to $\left.C_{97}\right)$ and SP10 $\left(C_{64}\right.$ to $\left.C_{97}\right)$ and in the E2 region $\mathrm{E} 2_{31}$ to E2 $2_{105}$ represented by SP21 (E2 21 to E2 $\left.{ }_{55}\right), \mathrm{SP} 22\left(\mathrm{E} 22_{51}\right.$ to E2 $\left.{ }_{75}\right)$, and SP23 (E2 $2_{81}$ to E2 $\left.{ }_{105}\right)$, there were few individuals with positive peptide-specific lymphoproliferative responses. Therefore, it was difficult to use statistical methods such as correlation analysis to deduce the minimum molecular determinants of a T-cell epitope. Thus, the nested peptides obtained by micro-TFMSA cleavage provided an alternative strategy to better define the $T$ determinants of the proliferative response stimulated by SP10 or by SP23 in high responders (Fig. 5). The nested set of peptides within $\mathrm{C}_{64}$ to $\mathrm{C}_{89}$ differed sequentially in the $\mathrm{N}$-terminal residue but had a common C-terminal residue. Peak lymphoproliferative responses (SI range, $\approx 10$ to 20 ) were stimulated by peptides having $\mathrm{N}$-terminal residues within $\mathrm{C}_{64}$ to $\mathrm{C}_{67}$. As peptides were shortened downstream of $\mathrm{C}_{67}$ on their $\mathrm{N}$-terminal ends, lymphoproliferative responses diminished rapidly. This capsid domain is of potential pathogenetic interest in that it binds antibody cross-reactive with a domain on the $52-\mathrm{kDa}$ molecule of rat pancreatic islet tumor cells (20). A proportion of human sera from patients with type I diabetes mellitus react with the $52-\mathrm{kDa}$ protein (19). Congenital rubella patients with diabetes express an increased frequency of HLA-B8 and DR4 (42), alleles expressed by this 
normal high responder to SP10. Thus, this capsid domain may mediate a known immunopathologic complication of rubella, diabetes, mellitus, through a relatively MHC restricted molecular mimicry.

The nested set of peptides within SP23 (E2 $2_{81}$ to $\left.E 2_{105}\right)$ obtained by micro-TFMSA cleavage had a common C-terminal residue but differed sequentially on the $\mathrm{N}$-terminal end. With two HLA-diverse SP23 responders, peak lymphoproliferative responses (SI range, $\approx 2$ to 5 ) were stimulated by peptides having $\mathrm{N}$-terminal residues within $\mathrm{E} 2_{81}$ to $\mathrm{E} 2_{84}$ (Fig. 5). Responses diminished rapidly as peptides were shortened downstream of E2 84 on their N-terminal ends.

\section{DISCUSSION}

In this study, synthetic peptides representing well-defined subsequences of RV structural proteins identified potential determinants of human cellular immunity to the virus. These immunoreactive peptides were initially defined by their proximity to conformationally independent (linear) B-cell determinants and by their content of predicted T-cell epitope motifs (41). The peptides studied stimulated varied but individually specific proliferation responses in PBMCs from a representatively large number of normal, RV-immune human donors with diverse HLA backgrounds. These responses were mediated largely by $\mathrm{CD} 4^{+} \mathrm{T}$ cells in association with HLA class II proteins. Structural blocking of either of these cell surface antigens by specific MAb binding markedly inhibited the peptide-stimulated proliferative response. Moreover, the increased coexpression of the CD4 and CDw29 markers among responder $T$ cells suggests that the SP-driven response is associated with immunologic memory $(1,6,7)$.

Each set of SPs based on discrete regions of the three RV structural proteins stimulated moderate lymphoproliferative responses (SI between 2 and 4) in 25 to $50 \%$ of the donor population. A smaller proportion (10 to 19\%) of donors (high responders) displayed robust SP-driven lymphoproliferative responses (SI of $\geq 4$ ). The robust in vitro lymphoproliferation of high responders to a number of SPs was comparable in thymidine uptake to that observed with intact RV antigen. Moreover, limiting-dilution analysis revealed single-hit or linear kinetics of lymphoproliferative responses of some high responders to N-terminal capsid SPs or to E1 SPs that may reflect a clonal response of these responders to a single T-cell proliferative epitope encoded within the SP. However, limiting-dilution kinetics showed considerable variability among individuals in lymphocyte recognition of T-cell determinants present in SPs, even within similar HLA-DR contexts. Some individuals did not recognize a peptide sequence in a single-hit fashion, implying that the processing or recognition of the peptide was more complex than the expansion of a single sequence-specific $\mathrm{T}$-cell clone. The limiting-dilution analyses suggest that the fine specificity of epitopes recognized by $\mathrm{T}$-cell clones vary from individual to individual. Thus, a slight increase in peptide length beyond the minimum determinant may be necessary to build agretypic diversity into a peptide sequence to render it more effective in a diverse MHC context. Such peptides could assume related but nonidentical conformations with different MHC alleles (15).

The finding of varied patterns of peptide-specific lymphoproliferative responses in this MHC-diverse population is consistent with the presumed role of MHC class II molecules in mediating the response. Nevertheless, more often than not a high response to a given SP was not DR allele specific, the notable exception being the $100 \%$ association of robust response to SP7 $\left(\mathrm{El}_{243}\right.$ to $\left.\mathrm{E1}_{266}\right)$ with HLA-DR3. Likewise, the relative lack of lymphoproliferative responses to certain sequences, notably SP15 $\left(E 1_{208}\right.$ to $\left.E 1_{239}\right)$ and SP10 $\left(C_{64}\right.$ to $\left.C_{97}\right)$, was not DR allele specific. Thus, those SPs which effectively drive in vitro lymphoproliferation may contain sequences with sufficient agretypic diversity for immunologic recognition by this outbred (human) donor population.

Ou et al. (36) recently reported that a single SP containing $\mathrm{C}_{1}$ to $\mathrm{C}_{30}$ failed to stimulate lymphoproliferative responses in any of six normal RV-immune adults tested, but the SP detected B-cell responses in all six individuals. They were able to show modest responses to other 28-residue subsequences of the capsid by restimulating $\mathrm{T}$-cell lines selected by lymphoproliferative stimulation with UV-inactivated RV antigen. These capsid peptide-reactive $\mathrm{T}$-cell lines were restricted to HLA-DR alleles $1,4,7$, and w9. Our set of shorter SPs (20 or fewer residues) within $C_{1}$ to $C_{29}$ elicited positive proliferative responses directly from PBMCs in $\approx 50 \%$ of a much larger population of RV-immune adults (105 individuals) but failed to bind human immune sera from even the most robust T-proliferative responders to these SPs (28). There was no significant HLA-DR restriction of the anticapsid lymphoproliferative responses even among high responders in our donor population.

The high frequency of $\mathrm{T}$ responders to the $\mathrm{N}$-terminal region of the capsid suggests an immunodominant role for this protein in rubella immunity. However, we observed variability in the fine specificity of $T$-proliferative epitopes in the N-terminal sequence, suggesting that it may be necessary to screen a moderately large population of immune donors to detect consistent peptide-specific lymphoproliferative responses. This could explain why $\mathrm{Ou}$ et al. failed to detect such responses among six individuals presented with $C_{1}$ to $C_{30}$. Alternatively, the slightly shorter subsequences used in our study may stimulate lymphoproliferation more efficiently. While agretypic diversity of a peptide sequence may be enhanced by residues extending beyond the minimum $T$ determinant, additional residues at a distance could adversely affect the functional expression of an immunodominant sequence (44). Why the $\mathrm{N}$-terminal capsid sequence of RV should be of importance in immunity is unclear. It is possible that this domain provides T-cell help for neighboring B-epitope domains on the capsid or even remote B-epitope domains on $\mathrm{RV}$ glycoproteins. The potential of a T-cell epitope to provide help for a distant B-cell epitope domain is illustrated by the demonstration of functioning chimeric immunogens combining $T$ - and B-cell epitopes from discrete viral proteins of hepatitis B virus (30), respiratory syncytial virus $(25)$, and other pathogens.

The starting point for the design of this set of SPs was the location of B-cell epitopes on RV structural proteins, specifically the conformationally independent or linear epitopes defined by murine MAbs (53). Most likely, the human humoral response to the $\mathrm{N}$-terminal $\mathrm{RV}$ capsid protein $\left(\mathrm{C}_{\mathbf{1}}\right.$ to $\mathrm{C}_{30}$ ) is predominantly directed to conformationally dependent epitopes not present in our subsequences of the region but simulated by the entire domain (36). The BALB/c mouse antibody response to $\mathrm{RV}$ infection which originally generated our set of defining MAbs (53) suggests that linear determinants are present in the immune repertoire, though in trace proportions. We suspect that the same is true for the human response to RV infection. Future studies with human MAbs to this region should better define the linear $B$ 
determinants of the human repertoire and their analogy with that of the mouse.

This study supports the usefulness of predicting immunoreactive peptides with an algorithm for T-epitope motifs (41). Of the 13 SPs with predicted T epitopes used, only 2 (SP15 and SP22) failed to stimulate significant lymphoproliferative responses in cells from at least 2 normal RV-immune individuals out of 17 or more tested at least twice. Correlation analysis suggested that the minimum sequence within SP1 $\left(C_{1}\right.$ to $\left.C_{18}\right)$ that determines lymphoproliferation is within $C_{9}$ to $\mathrm{C}_{18}$, which includes several amino acid residues immediately $\mathrm{N}$-terminal to a predicted motif at $\mathrm{C}_{14}$ to $\mathrm{C}_{18}$. This analysis either suggests an alternate location for the motif or reflects the influence of molecular context on the functional expression of a T epitope $(12,44,45)$. Two SPs, SP10 $\left(\mathrm{C}_{64}\right.$ to $\left.\mathrm{C}_{97}\right)$ and SP23 (E2 ${ }_{81}$ to E2 $\left.2_{105}\right)$, lacked predicted T-epitope motifs but did stimulate lymphoproliferative responses from a more limited though MHC-diverse subset of donors. The proportion of donors stimulated by SP23 (4 of 17 , or $24 \%$ ) is comparable to the proportion stimulated by several SPs containing predicted T-cell epitope motifs. Thus, the Rothbard-Taylor algorithm sometimes failed to predict relevant T-cell epitopes recognized by our RV-immune population.

An additional useful locator of relevant $\mathrm{T}$-cell epitopes could be their linear proximity to B-determinant domains. Our study identified immune-specific determinants of MHCdiverse human $\mathrm{T}$-lymphoproliferative responses in close linear proximity to linear B determinants on all three structural proteins of $\mathrm{RV}$, including a domain on $\mathrm{E} 1$ which may mediate virus-cell interaction. Both SP10 and SP23 contain B-determinant motifs predicted by hydrophilicity (17). The $\mathrm{N}$-terminal residues of the $\mathrm{T}$ determinants recognized by the responders (Fig. 5) are in both cases adjacent to predicted $B$ determinants at $\mathrm{C}_{68}$ to $\mathrm{C}_{73}$ and $\mathrm{E} 2_{93}$ to $\mathrm{E} 2_{98}$, respectively. Moreover, murine MAb-binding domains have been defined within E2 ${ }_{86}$ to $E 2_{105}$ (54). However, using 31-residue SPs spanning the entire RV capsid protein, Ou et al. (36) defined discrete $\mathrm{T}$ - and B-cell determinants recognized by human immune sera, but they were more often on distinct SPs. Thus, there may be additional T-cell epitopes within the RV-immune repertoire that are distant from B determinants. Nevertheless, proximity of $\mathrm{T}$ - and $\mathrm{B}$-epitopes has been previously found on influenza virus surface proteins $(2,13)$, on hepatitis B surface antigen (31), and on herpes simplex virus $\mathrm{gD}(10)$. Such proximity suggests that viral immunity elicits B-cell and MHC class II-restricted T-cell repertoires focused about common antigenic sites. If this is generally true, then identification of immunodominant helper T-cell determinants could lead to the identification of nearby B-cell determinants within relatively short, accessible sequences of viral structural proteins and vice versa, greatly facilitating the rational design of new synthetic vaccines against $R V$ and other agents. Moreover, with the recent demonstration that peptide fragments can mediate class I-restricted cytotoxic lymphocyte responses (47), there is now further rationale for incorporating selected cytotoxic $\mathrm{T}$ determinants into peptide immunogens. Such determinants may be important to achieve effective immune-mediated elimination of the predominant cell-associated phase of the RV replicative cycle. Synthetic peptides are currently being used to define the determinants of cytotoxic anti-RV immunity in further studies with our MHC-diverse human population.

\section{ACKNOWLEDGMENTS}

We are indebted to William T. Moore, of the Analytical Chemistry Center, The University of Texas Health Science Center at Houston, for help in the design, synthesis, and structural confirmation of SPs. Kyle Kennedy provided expert technical help with immunological assays.

This study was supported in part by grant AI26943 from the National Institutes of Health to J.S.W. and by a Young Investigator's Award to M.M. from the National Foundation for Infectious Diseases.

\section{REFERENCES}

1. Akbar, A. N., L. Terry, A. Timms, P. C. L. Beverley, and G. Janossy. 1988. Loss of CD45R and gain of UCHL1 reactivity is a feature of primed T cells. J. Immunol. 140:2171-2178.

2. Barnett, B. C., C. M. Graham, D. S. Burt, J. J. Skehel, and D. B. Thomas. 1989. The immune response of $\mathrm{Balb} / \mathrm{c}$ mice to influenza hemagglutinin: commonality of the B-cell and T-cell repertoires and their relevance to antigenic drift. Eur. J. Immunol. 19:515521.

3. Berzofsky, J. A., A. Bensussan, K. B. Cease, J. F. Bourge, R. Cheynier, Z. Lurhuma, J. J. Salaun, R. C. Gallo, G. M. Shearer, and D. Zagury. 1988. Antigenic peptides recognized by T-lymphocytes from AIDS viral envelope-immune humans. Nature (London) 334:706-708.

4. Berzofsky, J. A., C. D. Pendleton, M. Clerici, J. Ahlers, and D. R. Lucey. 1991. Construction of peptides encompassing multideterminant clusters of human immunodeficiency virus envelope to induce in vitro $\mathrm{T}$ cell responses in mice and humans of multiple MHC types. J. Clin. Invest. 88:876-884.

5. Buimovici-Klein, E., K. E. Weiss, and L. Z. Cooper. 1977. Interferon production in lymphocyte cultures after rubella infection in humans. J. Infect. Dis. 135:380-385.

6. Byrne, J. A., J. L. Butler, and M. D. Cooper. 1988. Differential activation requirements for virgin and memory $T$ cells. $J$. Immunol. 41:3249-3257.

7. Clement, L. T., N. Yamashita, and A. M. Martin. 1988. The functionally distinct subpopulations of human CD4+ helper/ inducer $T$ lymphocytes defined by anti-CD $45 R$ antibodies derive sequentially from a differentiation pathway that is regulated by activation-dependent post-thymic differentiation. J. Immunol. 141:1464-1470.

8. Colton, T. 1974. Statistics in medicine, p. 219-229. Little, Brown, and Co., Boston.

9. Cusi, M. G., G. M. Rossolini, C. Cellesi, and P. E. Valensin. 1988. Antibody response to wild rubella virus structural proteins following immunization with RA 27/3 live attenuated vaccine. Arch. Virol. 101:25-33.

10. DeFreitas, E. C., B. Dietzschold, and H. Koprowski. 1985. Human T-lymphocyte response in vitro to synthetic peptides of herpes simplex virus glycoprotein D. Proc. Natl. Acad. Sci. USA 82:3425-3429.

11. Dominguez, G., C. Y. Wang, and T. K. Frey. 1990. Sequence of the genome RNA of rubella virus-evidence for genetic rearrangement during togavirus evolution. Virology 177:225-238.

12. Gammon, G., N. Shastri, J. Cogswell, S. Wilbur, S. SadeghNasseri, U. Krzych, A. Miller, and E. E. Sercarz. 1987. The choice of T-cell epitopes utilized on a protein antigen depends on multiple factors distant from, as well as at the determinant site. Immunol. Rev. 98:53-71.

13. Graham, C. M., B. C. Barnett, I. Hartlmayer, D. S. Burt, R. Faulkes, J. J. Skehel, and D. B. Thomas. 1989. The structural requirements of class II $\left(\mathrm{I}-\mathrm{A}^{\mathrm{d}}\right)$-restricted T-cell recognition of influenza hemagglutinin: B-cell epitopes define T-cell epitopes. Eur. J. Immunol. 19:523-528.

14. Hayward, A. R. 1990. T-cell responses to predicted amphipathic peptides of varicella-zoster virus glycoproteins II and IV. J. Virol. 64:651-655.

15. Hill, C. M., J. D. Hayball, A. A. Allison, and J. B. Rothbard. 1991. Conformational and structural characteristics of peptides binding to HLA-DR molecules. J. Immunol. 147:189-197.

16. Honeyman, M. C., J. M. Forrest, and D. C. Dorman. 1974. Cell-mediated immune response following natural rubella and rubella vaccination. Clin. Exp. Immunol. 17:665-671.

17. Hopp, T. P., and K. R. Woods. 1981. Prediction of protein antigenic determinants from amino acid sequences. Proc. Natl. 
Acad. Sci. USA 78:3824-3828.

18. Julius, M. H., E. Simpson, and L. A. Herzenberg. 1973. A rapid method for the isolation of functional thymus-derived murine lymphocytes. Eur. J. Immunol. 3:645-649.

19. Karounos, D. G., and J. W. Thomas. 1990. Recognition of common islet antigen by autoantibodies from NOD mice and humans with IDDM. Diabetes 39:1085-1090.

20. Karounos, D. G., J. S. Wolinsky, and J. W. Thomas. Monoclonal antibody to rubella virus capsid protein recognizes a beta cell antigen. Submitted for publication.

21. Kerman, R. H., P. M. Kimball, and B. D. Kahan. 1991. Stronger immune responsiveness of blacks versus whites may account for renal allograft survival differences. Transplant. Proc. 23: $400-402$.

22. Lefkovits, I. 1979. Limiting dilution analysis, p. 356-370. In B. Pernis (ed.), Immunological methods. Academic Press, Inc., New York.

23. Lefkovits, I., and H. Waldmann. 1979. Limiting dilution analysis of cells in the immune system. Cambridge University Press, Cambridge.

24. Levely, M. E., C. A. Bannow, C. W. Smith, and J. A. Nicholas. 1991. Immunodominant $T$-cell epitope on the $F$ protein of respiratory syncytial virus recognized by human lymphocytes. J. Virol. 65:3789-3796.

25. Levely, M. E., M. A. Mitchell, and J. A. Nicholas. 1990. Synthetic immunogens constructed from T-cell and B-cell stimulating peptides ( $T: B$ chimeras): preferential stimulation of unique T- and B-cell specificities is influenced by immunogen configuration. Cell. Immunol. 125:65-78.

26. McCarthy, M., R. H. Kerman, and J. S. Wolinsky. 1990. An immunodominant domain within the rubella virus capsid protein contains T-cell and B-cell determinants. Presented at the American Society of Virology 9th Annual Meeting.

27. McCarthy, M., A. E. Lovett, and J. S. Wolinsky. Unpublished data.

28. McCarthy, M., and A. Overstreet. Unpublished data.

29. McCarthy, M., A. Overstreet, A. E. Lovett, and J. S. Wolinsky. Unpublished data.

30. Milich, D. R., J. L. Hughes, A. McLachlan, G. B. Thornton, and A. Moriarty. 1988. Hepatitis B synthetic immunogen comprised of nucleocapsid T-cell sites and an envelope B-cell epitope. Proc. Natl. Acad. Sci. USA 85:1610-1614.

31. Milich, D. R., J. E. Jones, A. McLachlan, G. Bitter, A. Moriarty, and J. L. Hughes. 1990. Importance of subtype in the immune response to the pre-S(2) region of the hepatis B surface antigen. II. Synthetic pre-S(2) immunogen. J. Immunol. 144:3544-3551.

32. Mitchell, L. A., T. Zhang, M. Ho, D. Décarie, A. J. Tingle, M. Zrein, and M. LaCroix. 1992. Characterization of rubella virusspecific antibody responses by using a new synthetic peptidebased enzyme-linked immunosorbent assay. J. Clin. Microbiol. 30:1841-1847.

33. Moore, W. T., J. S. Wolinsky, M. J.-F. Suter, T. B. Farmer, and R. M. Caprioli. 1992. Immunogenic synthetic peptide epitope mapping with structural validation using electrospray mass spectrometry, p. 183-197. In R. H. Angeletti (ed.), Techniques in protein chemistry III. Academic Press, Inc., San Diego, Calif.

34. Nath, A., B. Siagle, and J. S. Wolinsky. 1989. Anti-idiotypic antibodies to rubella virus. Arch. Virol. 107:159-167.

35. Nath, A., and J. S. Wolinsky. 1990. Antibody response to rubella virus structural proteins in multiple sclerosis. Ann. Neurol. 27:533-536.

36. Ou, D., P. Chong, B. Tripet, and S. Gillam. 1992. Analysis of Tand B-cell epitopes of capsid protein of rubella virus by using synthetic peptides. J. Virol. 66:1674-1681.

37. Partidos, C. D., C. M. Stanley, and M. W. Steward. 1991. Immune responses in mice following immunization with chimeric synthetic peptides representing B- and T-cell epitopes of measles virus proteins. J. Gen. Virol. 72:1293-1299.
38. Partidos, C. D., and M. W. Steward. 1990. Prediction and identification of a T-cell epitope in the fusion protein of measles virus immunodominant in mice and humans. J. Gen. Virol. 71:2099-2105.

39. Reid, R. H., C. A. Hooper, and B. R. Brooks. 1989. Computer simulations of a tumor surface octapeptide epitope. Biopolymers 28:525-530.

40. Rothbard, J. B., R. I. Lechler, K. Howland, V. Bal, D. D. Eckels, R. Sekaly, E. O. Long, W. R. Taylor, and J. R. Lamb. 1988. Structural model of HLA-DR1 restricted T-cell antigen recognition. Cell 52:515-523.

41. Rothbard, J. B., and W. R. Taylor. 1988. A sequence pattern common to T cell epitopes. EMBO J. 7:93-100.

42. Rubinstein, P., M. E. Walker, B. Fedun, M. E. Witt, L. Z. Cooper, and F. Ginsberg-Fellner. 1982. The HLA system in congenital rubella patients with and without diabetes. Diabetes 31:1088-1091.

43. Scopes, G. E., P. J. Watt, and P. R. Lambden. 1990. Identification of a linear epitope on the fusion glycoprotein of respiratory syncytial virus. J. Gen. Virol. 71:53-59.

44. Sercarz, E., A. Ametani, R. Apple, J. Cogswell, G. Gammon, and A. Miller. 1989. How successful a T-cell determinant will be depends on aleatory features of its molecular context. UCLA Symp. Mol. Cell. Biol. 113:37-45.

45. Sercarz, E., G. Gammon, and M. Palmer. 1990. T-cell dominance and the vaccine problem: modifying effects on immunogenicity by residues at a distance from the site of T-cell recognition. Semin. Immunol. 2:297-305.

46. Steele, R. W., S. A. Hensen, M. M. Vincent, D. A. Fuccillo, and J. A. Bellanti. 1974. Development of specific cellular and humoral immune responses in children immunized with live rubella. J. Infect. Dis. 130:449-453.

47. Townsend, A. R. M., J. Rothbard, F. M. Gotch, G. Bahadur, D. Wraith, and A. J. McMichael. 1986. The epitopes of influenza nucleoprotein recognized by cytotoxic T-lymphocytes can be defined with short synthetic peptides. Cell 44:959-968.

48. Trudel, M., F. Nadon, C. Seguin, G. Dianne, and M. La Croix. 1987. Identification of a synthetic peptide as part of a major neutralization epitope of respiratory syncytial virus. J. Gen. Virol. 68:2273-2280.

49. Trudel, M., F. Nadon, C. Seguin, P. Payment, and P. J. Talbot. 1987. Respiratory syncytial virus fusion glycoprotein: further characterization of a major epitope involved in virus neutralization. Can. J. Microbiol. 33:933-938.

50. Waxham, M. N., and J. S. Wolinsky. 1985. Detailed immunologic analysis of the structural polypeptides of rubella virus using monoclonal antibodies. Virology 143:153-165.

51. Wolinsky, J. S. 1990. Rubella virus, p. 815-840. In B. N. Fields, D. M. Knipe, R. M. Chanock, J. L. Melnick, B. Roizman, and R. E. Shope (ed.), Virology. Raven Press, New York.

52. Wolinsky, J. S., and M. McCarthy. Rubella. In J. S. Porterfield (ed.), Handbook of infectious diseases. Viruses, vol. 3. Arbovirus infections, viral hemorrhagic fevers, rabies and rubella, in press. B. C. Decker, Inc., Philadelphia.

53. Wolinsky, J. S., M. McCarthy, O. Allen-Cannady, W. Moore, R. Jin, S. N. Cao, A. Lovett, and D. Simmons. 1991. A monoclonal antibody defined epitope map of expressed rubella virus protein domains. J. Virol. 65:3986-3994.

54. Wolinsky, J. S., E. Sukholutsky, R. Jin, and W. T. Moore. 1992. Epitopes of rubella virus E2 glycoprotein-specific monoclonal antibodies defined by synthetic peptides. Presented at the American Society of Virology 11th Annual Meeting.

55. Wolinsky, J. S., E. Sukholutsky, and W. T. Moore. Unpublished data.

56. Wolinsky, J. S., E. Sukholutsky, W. T. Moore, B. Adame, and O. Allen-Cannady. 1991. Epitopes of two neutralizing rubella virus monoclonal antibodies are defined by an immunogenic synthetic peptide. Presented at the American Society of Virology 10th Annual Meeting. 